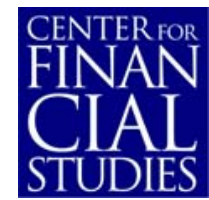

No. $2007 / 17$

Money in Monetary Policy Design under Uncertainty: The Two-Pillar Phillips Curve versus ECB-Style Cross-Checking

Günter W. Beck and Volker Wieland 


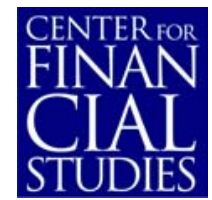

\section{Center for Financial Studies}

The Center for Financial Studies is a nonprofit research organization, supported by an association of more than 120 banks, insurance companies, industrial corporations and public institutions. Established in 1968 and closely affiliated with the University of Frankfurt, it provides a strong link between the financial community and academia.

The CFS Working Paper Series presents the result of scientific research on selected topics in the field of money, banking and finance. The authors were either participants in the Center's Research Fellow Program or members of one of the Center's Research Projects.

If you would like to know more about the Center for Financial Studies, please let us know of your interest.

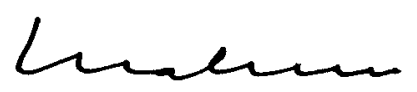

Prof. Dr. Jan Pieter Krahnen

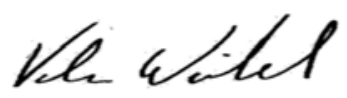

Prof. Volker Wieland, Ph.D. 


\title{
Money in Monetary Policy Design under Uncertainty: The Two-Pillar Phillips Curve versus ECB-Style Cross-Checking*
}

\author{
Günter W. Beck ${ }^{1}$ and Volker Wieland ${ }^{2}$ \\ 1st version: August 26, 2006 \\ This version: October 18, 2006
}

\begin{abstract}
:
The European Central Bank has assigned a special role to money in its two pillar strategy and has received much criticism for this decision. In this paper, we explore possible justifications. The case against including money in the central bank's interest rate rule is based on a standard model of the monetary transmission process that underlies many contributions to research on monetary policy in the last two decades. Of course, if one allows for a direct effect of money on output or inflation as in the empirical "two-pillar" Phillips curves estimated in some recent contributions, it would be optimal to include a measure of (long-run) money growth in the rule. In this paper, we develop a justification for including money in the interest rate rule by allowing for imperfect knowledge regarding unobservables such as potential output and equilibrium interest rates. We formulate a novel characterization of ECB-style monetary cross-checking and show that it can generate substantial stabilization benefits in the event of persistent policy misperceptions regarding potential output. Such misperceptions cause a bias in policy setting. We find that cross-checking and changing interest rates in response to sustained deviations of long-run money growth helps the central bank to overcome this bias. Our argument in favor of ECB-style cross-checking does not require direct effects of money on output or inflation.
\end{abstract}

JEL Classification: E32, E41, E43, E52, E58

Keywords: Monetary Policy, Quantity Theory, Phillips Curve, European Central Bank, Policy Under Uncertainty

\footnotetext{
This paper was prepared for the invited session on "Money in Monetary Policy” at the EEA 2006 Annual Congress, Vienna, August 24 28, 2006. A subset of this paper's findings has been summarized in a shorter paper submitted to the Journal of the European Economic Association under the title 'Money in Monetary Policy Design under Uncertainty: A Formal Characterization of ECB-Style CrossChecking'. We thank Katrin Assenmacher-Wesche, Stefan Gerlach and seminar participants at the invited session "Money in Monetary Policy” at the EEA 2006 Annual Congress for helpful comments. The usual disclaimer applies.

1 Goethe University Frankfurt and CFS; E-mail: gbeck@wiwi.uni-frankfurt.de

2 


\section{Introduction}

Contrary to the monetary policy strategies of the U.S. Federal Reserve and many inflationtargeting central banks, which assign no special role to monetary aggregates, the European Central Bank has maintained a separate and important role for money in its two pillar strategy. The ECB distinguishes an 'economic' and a 'monetary' pillar:'

- "Economic analysis assesses the short to medium-term determinants of price developments. The focus is on real activity and financial conditions in the economy. The economic analysis takes account of the fact that price developments over those horizons are influenced largely by the interplay of supply and demand in the goods, services and factor markets."

- "Monetary analysis focuses on a longer-term horizon than the economic analysis. It exploits the long-run link between money and prices. The monetary analysis mainly serves as a means of cross-checking, from a medium to long-term perspective, the short to medium-term indications for monetary policy coming from the economic analysis."

In terms of economic theory, the long-run link noted by the ECB is related to the equation of exchange, that is, the definition of the velocity of money. Rewritten in growth terms it relates money growth, inflation and output growth to the change in velocity. In the long-run, once output growth and the change in velocity have settled down to trend, the equation of exchange implies a proportional relationship between money growth and inflation. In terms of empirics, this relationship has manifested itself most clearly in periods of very high inflation. Recent empirical assessments, however, have re-emphasized its validity in periods of moderate to low inflation in leading industrial economies. ${ }^{2}$

On this basis, Gerlach $(2003,2004)$ has proposed to augment the standard Phillips curve, which accounts for shorter-term inflation dynamics, resource utilization gaps and inflationary shocks, with a measure of long-run or low-frequency money growth. ${ }^{3}$ His estimates indicate a direct effect of filtered money growth on inflation. Such an augmented Phillips curve unifies the two pillars of the ECB in a single assessment of inflationary risks, and-if treated as a structural relationship—-provides a rationale for including filtered money growth in the central bank's optimal interest rate rule. Consequently, optimal interest rate policy would embody a small but systematic response to ongoing monetary developments. The ECB's description of its strategy, however, does not rely on a direct effect of money on inflation in the Phillips curve. Rather, it

\footnotetext{
${ }^{1}$ See http://www.ecb.int/pub/pdf/other/monetarypolicy2004en.pdf.

${ }^{2}$ See, for example, Gerlach (2003, 2004), ECB (2004), Haug and Dewald (2004, Pill and Rautanen (2006), Assenmacher-Wesche and Gerlach (2006a, 2006b). Bordo and Filardo (2006) consider different inflation zones including low inflation and deflation.

${ }^{3}$ A similar proposal has been made by Neumann and Greiber (2004).
} 
focuses on the long-run link and its usefulness for identifying medium- to long-term inflationary risks. Thus, we aim to develop an alternative rationale for including money in the policy rule that stays as close as possible to the ECB's stated reasons. The ECB's former chief economist, Otmar Issing, wrote on the monetary pillar: "In line with the argument of a closer relationship between money and inflation at lower frequencies, the function ascribed to the monetary pillar is to reveal medium-term risks to price stability .." but "... there is no mechanical monetary policy reaction to deviations of M3 growth from the reference value" and "... cross-checking the information from the economic analysis with the information from the monetary pillar is ... a crucial element underpinning the robustness and medium-term policy orientation". He concludes: "you can also think of the monetary pillar as the institutionalized promise of what the ECB will continue to do in the future; cultivating, as far as possible, an approach to central banking geared towards constant learning and encompassing all available information relevant for monetary policy". 4

We formally characterize ECB-style cross-checking using a policy rule with two components. The first component aims to control inflationary risks based on a standard Phillips curve and aggregate demand relationship. Essentially, it is the optimal interest rate rule of an inflation-targeting central bank. If implemented successfully this rule should ensure that inflation averages around the central bank's inflation target. Its weakness is that it relies on knowledge of unobservables such as the equilibrium real interest rate and potential output that may be subject to large and persistent policy misperceptions. $^{5}$

The second component captures the idea of cross-checking using the long-run relationship between money and inflation. We assume that the central bank checks regularly whether a filtered money growth series adjusted for output and velocity trends averages around the inflation target. If the central bank obtains successive signals of a sustained deviation of inflation from target it adjusts interest rates accordingly.

Our simulations indicate that persistent policy misperceptions regarding potential output induce a policy bias that translates into persistent deviations of inflation and money growth from target. In this case, our "two-pillar" policy rule may effectively overturn the policy bias. Cross-checking relies on filtered series of actual money and output growth without requiring estimates of potential output. Nevertheless, it leads to adjustments in interest rate policy that offset the bias resulting from policy misperceptions. Indirectly, however, it helps the central bank to learn the proper level of interest rates.

\footnotetext{
${ }^{4}$ See Issing (2005).

${ }^{5}$ See, e.g, Orphanides (2003) and Orphanides et al. (2000a).
} 


\section{Money growth and inflation in the long run}

The equation of exchange defines velocity, $v_{t}=-m_{t}+p_{t}+y_{t}$, where $(m, y, p)$ denote the logarithms of money, output and the aggregate price level. Taking first differences we approximate the equation in growth terms:

$$
\Delta v_{t}=-\Delta m_{t}+\Delta p_{t}+\Delta y_{t}
$$

$\Delta$ is the first-difference operator. In the long-run, output growth and the change in velocity will settle down to trend and reveal a proportional relationship between money growth and inflation. In the short-run, however, fluctuations in velocity and output growth are likely to obscure this relationship. The behavior of velocity may be characterized as a function of the nominal interest rate, $i$, real output and money demand shocks, $\varepsilon^{m d}$, using a standard money demand equation:

$$
m_{t}-p_{t}=\gamma_{y} y_{t}-\gamma_{i} i_{t}+\varepsilon_{t}^{m d}
$$

Here, $\gamma_{y}$ denotes the income elasticity and $\gamma_{i}$ the semi-interest rate elasticity of money demand. Money demand shocks are assumed to be normally distributed with mean zero and variance $\sigma_{m d}^{2}$. Taking first differences, re-arranging (2) and combining with (1) we obtain:

$$
\Delta v=\left(1-\gamma_{y}\right) \Delta y+\gamma_{i} \Delta i+\Delta \varepsilon_{m d}
$$

Long-run equilibrium values (superscript *) can then be determined as follows. In the long-run, money demand shocks would average to zero, and the nominal interest rate would settle down to its steady state level. Thus, the long-run trend in velocity corresponds to $\Delta v_{t}^{*}=\left(1-\gamma_{y}\right) \Delta y_{t}^{*}$, and long-run inflation is proportional to long-run money growth adjusted for output and velocity trends: ${ }^{6}$

$$
\Delta p_{t}^{*}=\Delta m_{t}^{*}-\gamma_{y} \Delta y_{t}^{*}
$$

Recent studies obtained empirical support for this long-run relationship using various filters or frequency-specific estimation. And more interestingly, they have found money growth to lead inflation at this frequency. To give an example, Gerlach (2004) uses the following filter

$$
\mu_{t}^{f}=\mu_{t-1}^{f}+\lambda\left(\mu_{t}-\mu_{t-1}^{f}\right)
$$

to approximate long-run values of inflation and money growth. In his work, $\mu_{t}$ may alternatively stand for money growth, $\Delta m_{t}$, or money growth adjusted for output growth.

\footnotetext{
${ }^{6} \mathrm{~A}$ trend in velocity may not only arise from potential output growth $\Delta y_{t}^{*}$ with an income elasticity $\gamma_{y}$ different from unity, but also from other sources such as financial innovations (see Orphanides and Porter (2001) and Masuch, Pill and Willeke (2001)).
} 
In our paper we will follow equation (4) and adjust money growth using the estimate of the income-elasticity of money demand, i.e.

$$
\mu_{t}^{f}=\Delta m_{t}^{f}-\gamma_{y} \Delta y_{t}^{f}
$$

\section{Monetary policy design without money}

Most research on monetary policy rules in the last two decades has focused on models, in which the monetary transmission mechanism works as follows: the nominal interest rate affects the real interest rate due to price rigidity, the real rate influences the output gap via aggregate demand and the output gap impacts on inflation via a standard Phillips curve. Thus, monetary aggregates play no direct role in the transmission of policy from nominal interest rates to inflation. ${ }^{7}$ Money supply instead is determined recursively from a money demand equation.

To illustrate this point we use a simple New-Keynesian style model with backwardlooking expectations in the spirit of Svenssson (1997), Rudebusch and Svensson (1999) and Orphanides and Wieland (2000). The model consists of a Phillips curve and an aggregate demand equation:

$$
\begin{aligned}
\pi_{t}= & \pi_{t+1}^{e}+\alpha_{y}\left(y_{t}-y_{t}^{*}\right)+\varepsilon_{\pi, t}, \\
y_{t}-y_{t}^{*}= & \left(y_{t+1}^{e}-y_{t+1}^{*, e}\right)-\beta_{r}\left(i_{t}-\pi_{t+1}^{e}-r_{t}^{*}\right)+\varepsilon_{y, t}, \\
& \text { where } \pi_{t+1}^{e}=\pi_{t-1}, y_{t+1}^{e}-y_{t+1}^{* e}=y_{t-1}-y_{t-1}^{*} .
\end{aligned}
$$

$\pi_{t}=\Delta p_{t}$ denotes inflation, $\left(\varepsilon_{\pi, t}, \varepsilon_{y, t}\right)$ stand for zero-mean cost-push and demand shocks respectively with variances $\left(\sigma_{\pi}^{2}, \sigma_{y}^{2}\right), r^{*}$ denotes the long-run equilibrium interest rate and the superscript ${ }^{e}$ refers to market expectations, which we assume to be backwardlooking.

An inflation-targeting central bank would set the nominal interest rate $i_{t}$ in order to minimize expected discounted inflation deviations from target

$$
\min _{i_{t}, i_{t+1}, \ldots} E_{t}\left\{\sum_{s=t}^{\infty} \delta^{s-t}\left(\pi_{s}-\pi^{\star}\right)^{2}\right\}
$$

where $\pi^{*}$ denotes the central bank's inflation target and $\delta$ its discount factor. Consequently, optimal monetary policy corresponds to a Taylor-style interest rate rule, which responds to lagged inflation and output gaps but not to money growth:

$$
i_{t}^{o p t}=r_{t}^{*}+\pi_{t-1}+\frac{1}{\alpha_{y} \beta_{r}}\left(\pi_{t-1}-\pi^{*}\right)+\frac{1}{\beta_{r}}\left(y_{t-1}-y_{t-1}^{*}\right) .
$$

\footnotetext{
${ }^{7}$ Exceptions are studies of the so-called 'P-star' model, originally of Hallman, Porter and Small (1991), such as Gerlach and Svensson (2003) and Gerdesmeier, Motto and Pill (2002).
} 
The superscript 'opt' refers to 'optimal'.

To be clear, the central bank achieves the desired interest rate setting by conducting open-market operations that influence the money supply. Thus, the money supply is determined according to the money demand equation (2) consistently with the desired policy rate, current output and the price level. However, money does not appear as a variable in the central bank's optimal interest rate rule and the remainder of the economy is automatically insulated from money demand shocks. Of course, the model defined by equations (7), (8), (10) and (2) also exhibits the long-run relationship between money growth and inflation discussed in the preceding section and emphasized by the ECB's monetary pillar.

\section{The two-pillar Phillips curve and policy design}

Inspired by the evidence for the long-run relationship between money and inflation, Gerlach $(2003,2004)$ proposed to include a filtered measure of money growth or adjusted money growth in the estimation of the short-run Phillips curve. A simplified version of the two-pillar Phillips curve is given by

$$
\pi_{t}=\alpha_{\mu} \mu_{t}^{f}+\alpha_{\pi} \pi_{t-1}+\alpha_{y}\left(y_{t}-y_{t}^{*}\right)+\varepsilon_{\pi, t}
$$

where we define adjusted filtered money growth $\mu_{t}^{f}$ as in equations (5) and (6) and assume that the weights on filtered money growth and lagged inflation sum to one, i.e. $\alpha_{\pi}=1-\alpha_{\mu}$.

In this subsection, we intend to make just one simple point. Namely, if any central bank were to consider this empirical two-pillar Phillips curve as a structural relationship ${ }^{8}$ it would conclude that a measure of filtered money growth should enter in its interest rate rule. Replacing the standard accelerationist Phillips curve in (7) with the two-pillar Phillips curve (11) we proceed to derive the optimal interest rate rule for the model comprising equations (11), (8), (9) and (2):

$$
\begin{aligned}
i_{t}^{2 p}= & \frac{\alpha_{y} \beta_{r}}{\alpha_{y} \beta_{r}+\alpha_{\mu} \lambda \gamma_{i}} r_{t}^{*}+\frac{\alpha_{y} \beta_{r}}{\alpha_{y} \beta_{r}+\alpha_{\mu} \lambda \gamma_{i}} \pi_{t-1}+\frac{1-\alpha_{\mu} \lambda}{\alpha_{y} \beta_{r}+\alpha_{\mu} \lambda \gamma_{i}}\left(\frac{1-\alpha_{\mu}}{1-\alpha_{\mu} \lambda} \pi_{t-1}-\pi^{\star}\right) \\
& +\frac{\alpha_{y}}{\alpha_{y} \beta_{r}+\alpha_{\mu} \lambda \gamma_{i}}\left(y_{t-1}-y_{t-1}^{\star}\right)+\frac{\alpha_{\mu}}{\alpha_{y} \beta_{r}+\alpha_{\mu} \lambda \gamma_{i}}\left[(1-\lambda) \mu_{t-1}^{f}+\lambda \gamma_{i} i_{t-1}-\lambda \varepsilon_{m d, t-1}\right] .
\end{aligned}
$$

The superscript ${ }^{2 p}$ refers to the two-pillar Phillips curve underlying this rule. It is more complicated than the rule given by (10) because the nominal interest rate influences

\footnotetext{
${ }^{8}$ Gerlach typically refrains from a structural interpretation with the exception of Gerlach (2004) where he introduces long-run money growth as a proxy for market expectations of inflation. Theoretical foundations for direct effects of money on aggregate demand and inflation can be obtained from micro-founded models that allow for non-separability of money and consumption in household utility. Empirical implementations, however, have failed to detect strong direct effects (cf. Ireland (2004) and Andres et al. (2006)).
} 
inflation not only via aggregate demand but also via a small contribution of current money supply to filtered money growth, $\mu_{t}^{f}$. Substituting out this effect leaves us with the lagged interest rate and the lagged money demand shock in the rule. However, the most important new element is the lagged filtered (and adjusted) money growth rate $\mu_{t-1}^{f}$. Of course, if the coefficient on filtered money growth in the two-pillar Phillips curve, $\alpha_{\mu}$, is set to zero, the interest rule again collapses to the specification without money in (10).

\section{ECB-style cross-checking and policy design}

The interest rate rule derived in the preceeding section can be viewed as a possible interpretation of the ECB's two pillar strategy. Our understanding, however, is that the ECB's strategy as stated does not require a direct effect of money on inflation in the Phillips curve. The ECB's description of cross-checking suggests to us that it uses the monetary pillar to accumulate evidence signalling trend changes in inflation. The monetary pillar appears to stand for the ECB's concern for 'robustifying' its policy under uncertainty and is subjected to regular scrutiny and learning.

Thus, we develop an alternative characterization of ECB-style cross-checking that stays as close as possible to the ECB's own description. Our proposed interest rate rule has two components:

$$
i_{t}^{C C}=i_{t}^{E A}+i_{t}^{M A}
$$

Here the superscript $C C$ refers to cross-checking, $E A$ to the interest rate setting implied by the ECB's 'economic analysis' and $M A$ to an additive adjustment in interest rate setting that arises from the ECB's 'monetary analysis'. We set the first component equal to the optimal interest rate rule in the baseline model:

$$
i_{t}^{E A}=i_{t}^{o p t} \quad \text { as defined in equation (10). }
$$

This interest rate setting should ensure that inflationary risks based on a standard Phillips curve are controlled perfectly and inflation fluctuates randomly around the mean, $\pi^{*}$. However, this component relies on knowledge of unobservables such as the equilibrium real interest rate, $r^{*}$, or potential output, $y^{*}$, that may be subject to large and persistent policy misperceptions.

The second component, $i_{t}^{M A}$, is novel and captures the idea of cross-checking using the long-run relationship between money and inflation. This component is additive and persistent, because it is intended to offset persistent policy biases due to imperfect information. We assume that the central bank regularly tests whether filtered and adjusted money growth, $\mu^{f}$, still averages around the inflation target. Thus, the central 
bank computes the normally-distributed test statistic,

$$
\kappa=\frac{\mu_{t-1}^{f}-\pi^{*}}{\sigma_{\mu^{f}}}
$$

and checks whether $\kappa$ deviates from a critical value $\kappa^{c r i t} . \sigma_{\mu^{f}}$ denotes the standard deviation when $i_{t}^{E A}=i^{o p t}$ is implemented with correct values of potential output and the mean of $\mu^{f}$ corresponds to $\pi^{*}$. If the central bank obtains successive signals of a sustained deviation from target, i.e. ( $\kappa>\kappa^{c r i t}$ for $N$ periods) or $\left(\kappa<-\kappa^{c r i t}\right.$ for $N$ periods), it responds by adjusting interest rates accordingly. ${ }^{9}$

$$
i_{t}^{M A}= \begin{cases}i_{t-1}^{M A}+\left(\frac{1}{\alpha_{y} \beta_{r}}\right)\left(\mu_{t-1}^{f}-\pi^{*}\right) & \text { if } \kappa>\kappa^{c r i t} \text { or } \kappa<-\kappa^{c r i t} \text { for } N \text { periods } \\ i_{t-1}^{M A}+0 & \text { else }\end{cases}
$$

As long as $i_{t}^{E A}=i_{t}^{\text {opt }}$ is implemented with full knowledge of potential output, $y_{t}^{*}$ and the real equilibrium rate, $r^{*}$, cross-checking with regard to $i_{t}^{M A}$ will almost never lead to an adjustment in interest rates. Under imperfect knowledge, however, cross-checking may once in a while have a very important effect on interest rate policy. ${ }^{10}$

\section{Cross-checking and policy misperceptions}

Recent research exploiting data on historical revisions to real-time estimates of the output gap has identified very persistent policy misperceptions. ${ }^{11}$ The persistence of measurement errors arises primarily from biased estimates of unobservable potential output, since revisions to actual output decline more rapidly than those to the output gap. Thus, if a central bank relies on potential output measures in policy design, its policy stance may be biased for a sustained period of time. To illustrate this effect we define the policymaker's estimate of potential output, $\hat{y}_{t}^{*}=y_{t}^{*}+$ bias $_{t}$, as the sum of true potential output and a measure of the misperception denoted by bias $t$, and include it in the baseline rule:

$$
i_{t}^{E A}=i_{t}^{o p t}=r_{t}^{*}+\pi_{t-1}+\frac{1}{\alpha_{y} \beta_{r}}\left(\pi_{t-1}-\pi^{*}\right)+\frac{1}{\beta_{r}}\left(y_{t-1}-y_{t-1}^{*}-\text { bias }_{t-1}\right) .
$$

\footnotetext{
${ }^{9}$ The response coefficient on inflation deviations from target is the same as in $i_{t}^{E A}$, namely $\frac{1}{\alpha_{y} \beta_{r}}$.

${ }^{10}$ The two parameters of $i_{t}^{M A}, \kappa^{c r i t}$ and $N$ play different roles. $\kappa^{\text {crit }}$ reflects the probability that an observed deviation of $\mu^{f}$ from $\pi^{\star}$ is purely accidental (for example a $5 \%$ or $1 \%$ significance level). $N$ defines the number of successive deviations in excess of this critical value. Thus, the greater $N$ the longer the central bank waits to accumulate evidence of a sustained policy bias. For example, if $\kappa^{\text {crit }}$ is set to the $1 \%$ critical value for the normal distribution (2.575) and the critical number of periods of sustained deviations $N$ is set to 4 , the probability of such an event in the absence of policy misperceptions would be less than $10^{-8}$.

${ }^{11}$ See Orphanides (2003) and Orphanides et al. (2000) who estimate a worst-case process of misperceptions with a near unit root (0.96) and standard deviation of $3.77 \%$ using quarterly revisions from 1966 to 1994.
} 
The resulting bias in interest rate policy will induce a persistent deviation of inflation from target. For example, if the central bank's estimate of potential output were to remain permanently $1 \%$ above its true level (i.e. bias $_{t}=1 \forall t$ ), average inflation would increase by $\left(\alpha_{y} \beta_{r}\right)\left(\beta_{r}\right)^{-1}$ percentage points.

To illustrate this point further we calibrate the model with the standard Phillips curve and backward-looking expectations defined by equations (7), (8) and (2). The calibration of the parameters is summarized in Table 1. We then simulate the interest rate rule (17)

Table 1: Calibration

\begin{tabular}{|c|c|c|}
\hline Parameter & Value & Economic interpretation \\
\hline$-\beta_{r}$ & -1 & $\begin{array}{l}\text { Real interest rate elasticity of aggregate demand (in line } \\
\text { with Andres et al. (2006) and Ireland (2004)). }\end{array}$ \\
\hline$\alpha_{y}$ & 0.5 & $\begin{array}{l}\text { Elasticity of Phillips curve w.r.t. output gap (broadly in } \\
\text { line with Gerlach (2004)). }\end{array}$ \\
\hline$\gamma_{y}$ & 0.1 & $\begin{array}{l}\text { Income elasticity of money demand (in line with Andes } \\
\text { et al. (2006) and Ireland (2004)). }\end{array}$ \\
\hline$-\gamma_{i}$ & -0.4 & $\begin{array}{l}\text { Interest rate elasticity of money demand (in line with An- } \\
\text { dres et al. (2006) and Ireland (2004)). }\end{array}$ \\
\hline$\lambda$ & 0.2 & $\begin{array}{l}\text { Weighting parameter of filter (broadly in line in Gerlach } \\
(2004) \text { ) }\end{array}$ \\
\hline$r^{*}, \Delta y_{t}^{*}, \pi^{\star}$ & 2 & $\begin{array}{l}\text { Equilibrium real interest rate, potential output growth and } \\
\text { inflation target }\end{array}$ \\
\hline$\sigma_{\pi}, \sigma_{y}, \sigma_{m d}$ & 0.8 & $\begin{array}{l}\text { Standard deviation of cost-push, demand and money de- } \\
\text { mand shocks }\end{array}$ \\
\hline$\sigma_{\mu f}$ & 0.38 & Standard deviation of $\mu^{f}$ \\
\hline$\kappa^{c r i t}$ & $1 \%$ & Critical value for the cross-checking rule. \\
\hline$N$ & 4 & $\begin{array}{l}\text { Number of periods required for a sustained deviation in } \\
\text { the cross-checking rule. }\end{array}$ \\
\hline
\end{tabular}

with the following sequence of policy misperceptions:

$$
\begin{array}{ll}
\text { for } t=(1,10) & \operatorname{bias}(t)=0 \\
\text { for } t=(11,12,13,14) & \operatorname{bias}(t)=(1,2,3,4) \\
\text { for } t=(15,100) & \operatorname{bias}(t)=4 \\
\text { for } t=(101,102,103) & \operatorname{bias}(t)=(3,2,1) \\
\text { for } t=(104,200) & \operatorname{bias}(t)=1
\end{array}
$$

The central bank's initial estimate of potential output is assumed to coincide with the true value. In periods 11 to 14 the central bank begins to overestimate potential output leading to a bias of $4 \%$ from period 14 onwards. In the calibrated model this misperception will cause a bias of $-4 \%$ in the central bank's interest rate response to short-run inflationary risks. Ultimately, this policy bias will induce an increase in average inflation of 2 percentage points. Accordingly, money growth and the long-run level of nominal interest rates will also rise by 2 percentage points. ¿From period 100 onwards the central bank's overestimate of potential output declines to $1 \%$ and the resulting deviation in 
average inflation to 0.5 percentage points.

Figure 1: Output Gap Misperceptions and the Money-Inflation Link
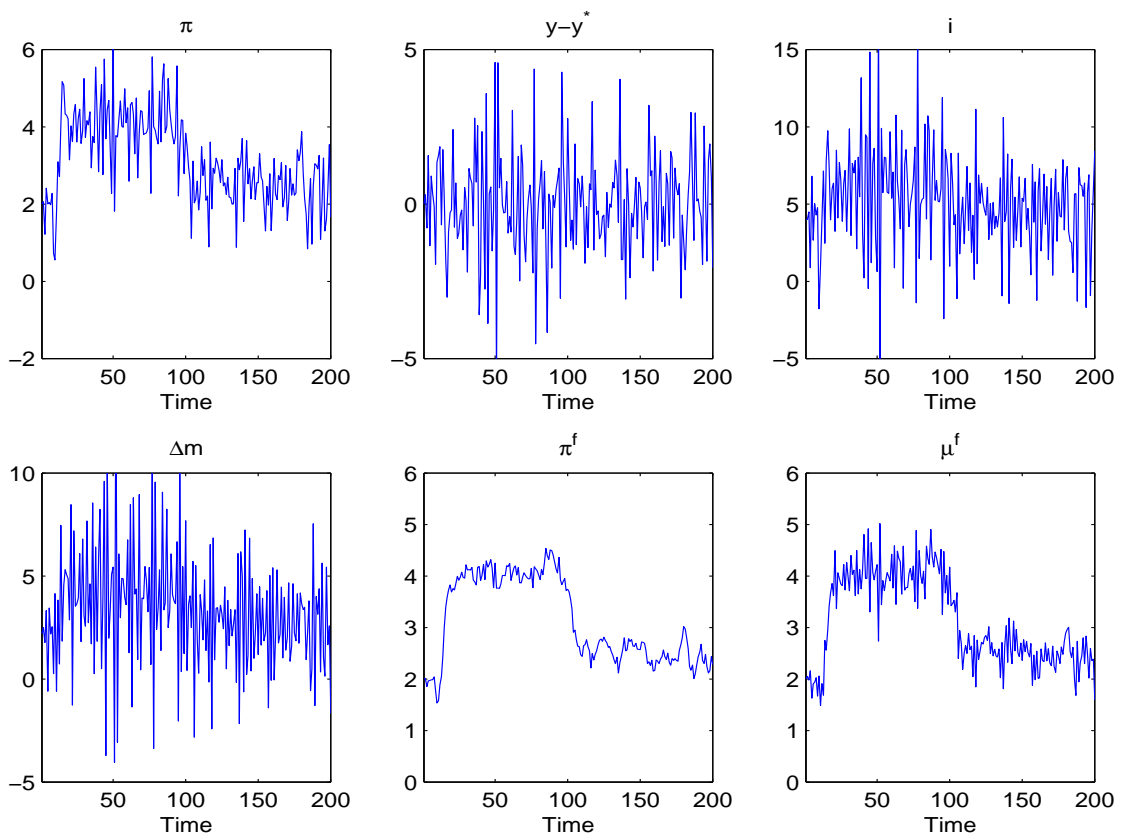

Figure 1 presents a simulation of the consequences of policy misperceptions for a single draw of normally-distributed cost-push, demand and money demand shocks. Given the many alternative sources of short-run fluctuations in inflation the persistent increase due to policy misperceptions cannot be immediately read from inflation realizations. Nevertheless, the filtered measures of inflation, $\pi^{f}$, and money growth, $\Delta m^{f}$, eventually reveal the increase in average money growth and inflation. This simulation shows how policy misperceptions regarding potential output would render the long-run relationship between money growth and inflation quite apparent in the data. In the short run, however, money growth may deviate substantially from inflation due to movements in interest rates and output as well as money demand shocks.

This simulation emphasizes the weakness of the policy rule, $i_{t}^{E A}=i^{o p t}$, in the event of persistent misses on potential output. A similar effect would arise from incorrect estimates of the equilibrium real interest rate $r^{*}$. Of course, one may argue that the process of misperceptions in (17) is an extreme example and that the central bank will learn from its mistakes. Thus, we proceed to show that cross-checking as defined by the rule in equation (16) provides a convenient and effective avenue for learning and correcting the central bank's policy bias.

We repeat the preceding simulation using the cross-checking rule, $i_{t}^{C C}$, defined by (16) which includes an additive and persistent adjustment in the event of sustained deviations of filtered (adjusted) money growth from target. The outcome is reported in Figure 2. We have dropped the panel with actual money growth, $\Delta m$, and have instead 
included a panel reporting the bias in the central bank's estimate of potential output, bias $_{t}$, and the adjustment in interest rates due to monetarist cross-checking. This adjustment corresponds to $i_{t}^{M A}$ as defined in equations (15) and (16). The cross-checking rule

Figure 2: Output Gap Misperceptions and ECB-Style Cross-Checking
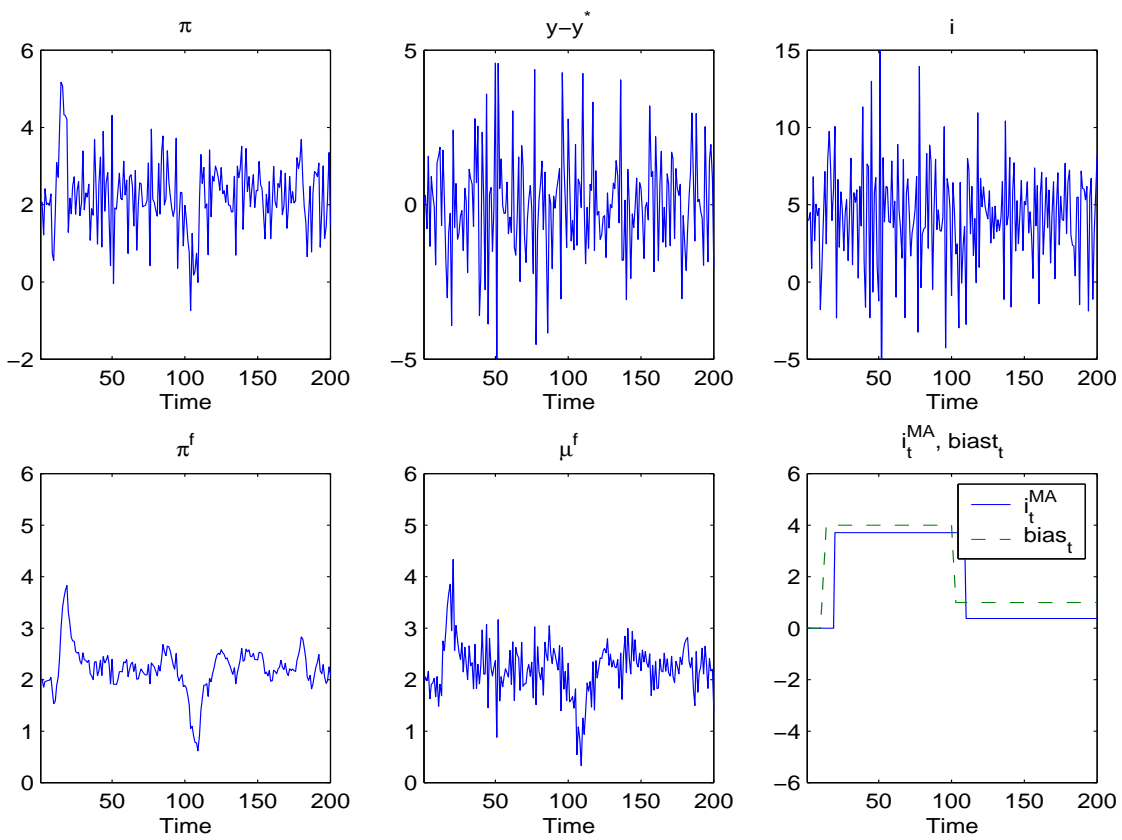

responds to the increase in filtered money growth, $\mu_{t-1}^{f}$, fairly quickly after the policy bias has arisen. The interest rate adjustment of $\left(\frac{1}{\alpha_{y} \beta_{r}}\right)\left(\mu_{t-1}^{f}-\pi^{*}\right)$ almost perfectly offsets the policy bias arising from potential output, $\left(\frac{1}{\beta_{r}}\right)\left(\right.$ bias $\left._{t-1}\right)$. Once the misperception of potential output declines after period 100, cross-checking soon leads to another adjustment of interest rates. In the preceding simulation the parameters of the cross-checking rule were set as follows: $\kappa^{\text {crit }}$ was set to the $1 \%$ critical value (2.575) and the number of periods required for a sustained deviation, $N$, was equal to 4 periods. The parameter $\lambda$, which determines how flexibly filtered money growth, $\mu_{t}^{f}$, responds to innovations was set to 0.2 .

To assess the sensitivity of our findings we draw 1000 series of shocks of length 200 from a normal distribution and use them to conduct a set of alternative simulations. Some of the findings are reported in Figure 3. The bottom left panel of Figure 3 reports the average path of the interest rate adjustment due to monetary cross-checking, i.e. $i_{t}^{M A}$, over 1000 simulations under the same parameter settings as in the single simulation displayed in Figure 2. This panel confirms that, on average, cross-checking leads to the appropriate interest rate adjustments offsetting the policy bias due to output gap misperceptions. The other panels in Figure 3 consider alternative values of $\lambda$ and $\kappa^{\text {crit }}$. Reducing $\lambda$ to 0.1 implies smoother filtering of money growth. Consequently, it takes longer to detect a persistent change and the interest adjustment from cross-checking 
Figure 3: Sensitivity Analysis Regarding the Performance of Cross-Checking
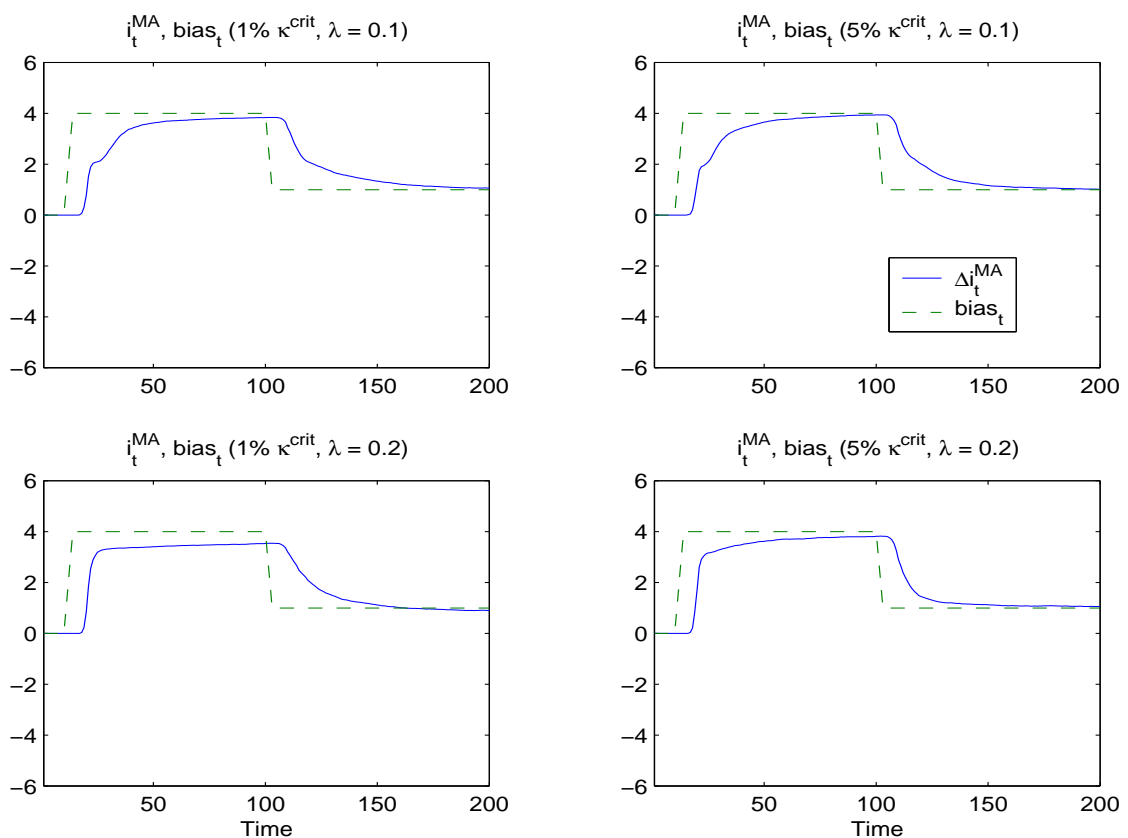

happens somewhat later in the top left panel than in the bottom left panel of Figure 3. Lowering $\kappa^{\text {crit }}$ to the 5-percent level (i.e. 1.96) renders cross-checking more sensitive to trend changes in money growth. Consequently, the interest-rate adjustments happen somewhat earlier in the second column of panels than in the first column.

\section{Outlook}

We have reviewed two possible rationales for including a smoothed measure of money growth in the central bank's interest rate rule. First, we have confirmed that the two-pillar Phillips curve presented in the recent literature-if considered a structural relationshipwould provide such a rationale. More interestingly, however, we have also shown that money can still play a very useful role in the central bank's interest rate rule if the economy corresponds to a more standard model, which does not incorporate a direct effect of money on inflation.

We have presented a novel, formal characterization of ECB-style cross-checking. To our knowledge this is the first formal characterization of the ECB's two pillar strategy with cross-checking as an interest rate rule. Under the unrealistic assumption that the true values of potential output and equilibrium real interest rates are known to the central bank our specification of cross-checking would never come into play. However, with imperfect knowledge there is a possibility of policy misperceptions. These misperceptions may generate sustained deviations of inflation from target. Due to the long-run link 
between money growth and inflation these deviations are also apparent in filtered measures of money growth. Thus, a central bank that responds to persistent and significant deviations of money growth by adjusting interest rates can effectively offset the policy bias arising from misperceptions about potential output and other unobservables.

Our findings open up several interesting avenues for further research. For example, allowing for unforeseen, permanent shifts in velocity, i.e. shifts in money demand parameters, the information content of long-run money growth would depend on how quickly the central bank learns the new parameter values. ${ }^{12}$ Furthermore, we have focused on strict inflation targeting with backward-looking expectations. In this case, cross-checking for persistent shifts is relatively straightforward as inflation and adjusted money-growth are expected to be white-noise processes. Extending the analysis to allow for partially forward-looking market expectations would not change this feature of our economy. However, flexible inflation targeting (with the output gap in the central bank's loss function) would introduce mean reversion in inflation and adjusted money growth dynamics. In this case, a more sophisticated test may be required for cross-checking. Finally, our baseline model may be extended to render filtered money growth a leading indicator of filtered inflation, such that it clearly dominates filtered inflation as the object of cross-checking.

\section{References}

Andres, Javier, David J. Lopez-Salido and Javier Valles, 2006, Money in an Estimated Business Cycle Model of the Euro Area, Economic Journal 116, 457-477.

Assenmacher-Wesche, Katrin and Stefan Gerlach, 2006a, Interpreting Euro Area Inflation at High and Low Frequencies, BIS Working Paper No. 195.

Assenmacher-Wesche, Katrin and Stefan Gerlach, 2006b, Money at Low Frequencies, Paper prepared for the invited session on "Money in Monetary Policy" at the EEA 2006 Annual Congress, Vienna.

Bordo, M. and A. Filardo, 2006, Money Still Makes the World Go Round: The Zonal View, Paper prepared for the invited session on "Money in Monetary Policy" at the EEA 2006 Annual Congress, Vienna.

ECB, 2004, Monetary Analysis in Real Time, Monthly Bulletin, October 2004.

Gerdesmeier, D., R. Motto and H. Pill, 2002, Paradigm Uncertainty and the Role of Monetary Developments in Monetary Policy Rules, Paper presented at the ECB workshop The Role of Policy Rules in the Conduct of Monetary Policy, Frankfurt.

Gerlach, Stefan, 2003, The ECBs Two Pillars, CEPR Discussion Paper, No. 3689.

Gerlach, Stefan, 2004, The Two Pillars of the European Central Bank, Economic Policy 40, 389-439.

\footnotetext{
${ }^{12}$ For a practical example see Orphanides and Porter (2001).
} 
Gerlach, S. and L. Svensson, 2003, Money and Inflation in the Euro-Area: A Case for Monetary Indicators? Journal of Monetary Economics 50, pp. 1649-1672.

Hallman, J., R. Porter, and D. Small, 1991, Is the Price Level Tied to the M2 Monetary Aggregate in the Long Run?, American Economic Review, 81 (September), pp. 841-58.

Haug, A. and W. Dewald, 2004, Longer-term Effects of Monetary Growth on Real and Nominal Variables, ECB Working Paper No 382.

Ireland, Peter N., 2004. Money's Role in the Monetary Business Cycle, Journal of Money, Credit and Banking, 36 (6), 969-83.

Issing, Otmar, 2005, The Monetary Pillar of the ECB, paper prepared for the conference "The ECB and its Watchers VII", 3 June 2005.

Masuch, Klaus, Huw Pill and Caroline Willeke, 2001, Framework and Tools for Monetary Analysis, in, Klöckers, Hans-Joachim and Caroline Willeke, eds., 2001, Monetary Analysis: Tools and Applications, ECB.

Neumann, M. J. M. and C. Greiber, 2004, Inflation and Core Money Growth in the Euro Area, Discussion Paper 36, Economic Research Centre of the Deutsche Bundesbank.

Orphanides Athanasios, 2003, The Quest for Prosperity without Inflation, Journal of Monetary Economics, 50 (3), 633663.

Orphanides, Athanasios and Richard Porter, 2001, Money and Inflation: The Role of Information regarding the Determinants of M2 Behavior, in, Klöckers, Hans-Joachim and Caroline Willeke, eds., 2001, Monetary Analysis: Tools and Applications, ECB.

Orphanides, Athanasios, Richard D. Porter, David Reifschneider, Robert Tetlow and Frederico Finan, 2000, Errors in the Measurement of the Output Gap and the Design of Monetary Policy, Journal of Economics and Business, 52 (1/2), 117-141.

Orphanides, Athanasios and Volker Wieland, 2000, Inflation Zone Targeting, European Economic Review, 44 (7) , 1351-1387.

Pill, Huw, and Thomas Rautananen, 2006, Monetary Analysis - The ECB Experience, Paper presented at the conference "The ECB and its Watchers VIII", 5 May 2006.

Rudebusch, G. and L. Svensson. 1999. Policy Rules for Inflation Targeting. in, Taylor, J.B., ed., Monetary Policy Rules, NBER and Chicago Press.

Svensson, Lars E.O., 1997, Inflation Forecast Targeting: Implementing and Monitoring Inflation Targets. European Economic Review 41 (6), 1111 - 1146. 


\section{CFS Working Paper Series:}

No.

Author(s)

2007/16

Silvio Colarossi

Andrea Zaghini

2007/15 Annamaria Lusardi

Olivia S. Mitchell

2007/14 Jean Boivin

Marc P. Giannoni

Ilian Mihov

2007/13 Virgiliu Midrigan

2007/12 Michael Woodford

2007/11 Lars E. O. Svensson Noah Williams

2007/10 Alessandro Calza Tommaso Monacelli Livio Stracca

2007/09 Mark Gertler Antonella Trigari

2007/08 Olivier Blanchard Jordi Galí

2007/07 Kai Christoffel

Keith Kuester

Tobias Linzert
Title

Gradualism, Transparency and Improved

Operational Framework: A Look at the Overnight

Volatility Transmission

Financial Literacy and Retirement Preparedness:

Evidence and Implications for Financial Education Programs

Sticky Prices and Monetary Policy: Evidence from Disaggregated U.S. Data

Menu Costs, Multi-Product Firms, and Aggregate Fluctuations

Robustly Optimal Monetary Policy with NearRational Expectations

Bayesian and Adaptive Optimal Policy under Model Uncertainty

Mortgage Markets, Collateral Constraints, and Monetary Policy: Do Institutional Factors Matter?

Unemployment Fluctuations with Staggered Nash Wage Bargaining

A New Keynesian Model with Unemployment

Identifying the Role of Labor Markets for

Monetary Policy in an Estimated DSGE Model

Copies of working papers can be downloaded at http://www.ifk-cfs.de 